\title{
Accurate Investigation of the Effect of Temperature and Pressure on the Transport coefficients of Carbon Dioxide as an Environmental Pollutant Gas with the Aid of Laser Application (3)
}

\author{
R. Ghazy ${ }^{\#}$ N. Hendawy*, S. Said*, and H. Nafie* \\ Laser Lab., Physics Department, Faculty of Sciences, Tanta University. \\ * Physics Department, Faculty of Sciences, Benha, Zagazig University.
}

In this work, the determined refractive indices of Carbon Dioxide gas in terms of both $\mathrm{CO}_{2}$ - temperature and $\mathrm{CO}_{2}$-pressure were used to determine the transport phenomena of this gas with the atmosphere. The transport phenomena was indicated with the transport coefficient which means the viscosity coefficient $\eta$, the diffusion Coefficient $D$, and thermal conductivity $\chi$ of $\mathrm{CO}_{2}$. The values of these coefficients were determined and its behavior depending on both pressure and temperature of the investigated gas, $\mathrm{CO}_{2}$. The rate of change of these coefficients with respect to $\mathrm{CO}_{2}$-pressure at constant temperature of $\mathrm{CO}_{2}$, $(d D / d p)_{T, \lambda},(d \eta / d p)_{T, \lambda}$, and $(d \chi / d p)_{T, \lambda}$ were determined. In addition, the rate of change of the same coefficients with respect to $\mathrm{CO}_{2}$-temperature at constant $\mathrm{CO}_{2}$-pressure $(d D / d T)_{p, \lambda},(d \eta / d T)_{p, \lambda}$, and $(d \chi / d T)_{p, \lambda}$ were also determined. All of these parameters were investigated at selected laser wavelengths, 476, 488, 502 , and $514.5 \mathrm{~nm}$. The graphs shown were at $\lambda=488 \mathrm{~nm}$ as an example.

\section{Introduction:}

Several reports have addressed the issue of weather and mortality; extreme temperatures have been associated with increased daily mortality in numerous regions of the world [1,2]. Mortality has also been observed to increase during periods of three or more days of unusual temperatures during summer or winter, showing that temperature variability is an important determinant of human health effects $[1,3]$. It has been suggested that weather and temperature may modify the effects of air pollution on health both at high temperatures [4]. The Intergovernmental Panel on Climate Change (IPCC) [5] has projected that atmospheric concentrations of carbon dioxide could double in the next 50-100 years. A doubling of atmospheric concentrations of $\mathrm{CO}_{2}$ could result in an increase in average global surface air temperatures of $1-3^{\circ} \mathrm{C}$ because 
of the greenhouse effect. In addition, because approximately $65 \%$ of atmospheric $\mathrm{CO}_{2}$ comes from combustion of fossil fuels, increasing concentrations of $\mathrm{CO}_{2}$ could also be accompanied by increasing concentrations of other air pollutants, particularly in large urban areas. An increase in surface air temperatures could accompany a greater frequency and duration of heat waves. The frequency of extremely hot days [5] in temperate climates approximately doubles for every $2-3^{\circ} \mathrm{C}$ increase in temperature during the average summer. Because heat waves often occur in large metropolitan areas during warm summer months, these large cities could experience an increase in the incidence of heat-related morbidity and mortality [6].

The phenomena of diffusion, viscosity, and thermal conductivity are all physically similar in that they involve the transport of some physical property through the gas or liquid. Ordinary diffusion is the transfer of mass from one region to another because of a gradient in the concentration; viscosity is the transport of momentum through the gas because of a gradient in the velocity; and thermal conductivity is the transport of thermal energy resulting from the existence of thermal gradients in the gas. These properties are appropriately termed "transport phenomena." We present here a description of these phenomena in terms of an ultra-simplified kinetic theory. Although very crude arguments are used throughout, it is nevertheless possible to obtain expressions, which describe the primary dependence of the transport coefficients upon the temperature and pressure and also upon the mass and size of the molecules in the gas [7].

\section{Theory}

In any real gas the molecules moves in all directions and their velocities are distributed over a very wide range. When two molecules come close to one another they undergo very complex interactions, since real molecules attract one another at large distances and repel one another when the intermolecular separation is quite small. In spite of the complicated behavior of the molecules, surprisingly good descriptions of the transport properties may be obtained if we consider the following very unrealistic model for a gas containing $\mathrm{N}$ molecules per unit volume $[7,8]$ :

(i) The molecules are rigid, non-attracting spheres with diameter $\sigma$.

(ii) All the molecules travel with the same speed; a reasonable choice for the molecular speed seems to be the arithmetic mean speed, $\Omega=(8 \mathrm{kT} / \mathrm{m} \pi)^{1 / 2}$, which may be calculated from the velocity distribution function.

(iii) All the molecules travel in a direction parallel to one of the coordinate axes, that is, one-sixth of them are traveling in the $(+x)$ direction one-sixth in the $(-\mathrm{x})$-direction, one-sixth in the $(+\mathrm{y})$-direction and so forth. 
Let us begin by examining the dependence of the rate of collisions, $\Gamma$, upon the size, number density, and average speed of the molecules. Consider a single molecule, which is moving in the $(+\mathrm{z})$-direction, and let us inquire as to the frequency with which it collides with the other molecules in the gas. Certainly it will undergo no collisions with the other molecules moving in the $(+\mathrm{z})$-direction, since they are all moving with the same speed, $\Omega$. With respect to those molecules moving in the (-z)-direction, however, it has a relative velocity of $2 \Omega$. This means that during a time interval $\Delta \mathrm{t}$ the molecules whose centers lie within a cylinder of cross-section $\pi \sigma^{2}$ and length $2 \Omega \Delta t$ will undergo collisions with the molecule on which our attention has been focused (assuming that the latter is not deflected by the collisions).

Since there are $\mathrm{N}$ molecules per unit volume and since one-sixth of them are moving in the (-z)-direction there will be $\left(\frac{1}{3} \pi N \sigma^{2} \Omega\right)$ collisions per unit time with this molecule. Similarly, the molecules moving in the $(+z)$-direction has a velocity of $(\sqrt{2} \Omega)$ relative to those molecules moving in the $(+x)$ - direction; hence there are $\left(\frac{\sqrt{2}}{6} \pi N \sigma^{2} \Omega\right)$ collisions per unit time with these molecules. The same result is obtained for molecules moving in the (-x), (-y) and (+y)directions, so that altogether there are [7]:

$$
\Gamma=\xi \mathrm{N} \pi \sigma^{2} \Omega=\xi \mathrm{p}_{\mathrm{r}} \sigma^{2}(8 \pi / \mathrm{mkT})^{1 / 2}
$$

Collisions suffered by one molecule per unit time, where ${ }^{\prime \prime}=\frac{1}{3}+\frac{2}{3} \sqrt{2}$. The second expression given in Eqn. 1 for $\Gamma$ was obtained by using $\mathrm{p}_{\mathrm{r}}=\mathrm{N}$ kT (ideal gas law) and $\Omega=\sqrt{8 \mathrm{kT} / \mathrm{m} \pi}$. (If one were to assume that the molecular motion takes place in all directions and that the velocity distribution is Maxwellian, the same result is obtained, except that is, $\xi=1.414$, as compared with the approximate 1.276).

Since the gas we are considering is composed of impenetrable elastic spheres, a collision between two molecules is well defined. This makes it possible to introduce a quantity known as the mean free path, which is the average distance traversed by a molecule between two collisions. Thus a molecule moving with speed $\Omega$, during a long time interval $\Delta \mathrm{t}$ (that is, a time interval long compared with the average time interval between collisions), will travel a distance $\Omega \Delta \mathrm{t}$; if the molecule suffers $\Gamma$ collisions per unit time, during the long time interval $\Delta t$, the molecule will collide $\Gamma \Delta t$ times. Hence, the average distance traversed by the molecule between two collisions, that is, the mean free path, is [9]: 


$$
L=\frac{\Omega \Delta t}{\Gamma \Delta t}=\frac{\Omega}{\Gamma}
$$

Substitution of Eqn.1 into Eqn.2 gives [9]:

$$
\mathrm{L}=\left(1 / \xi \mathrm{N} \pi \sigma^{2}\right)=\left(\mathrm{kT} / \xi \mathrm{p}_{\mathrm{r}} \pi \sigma^{2}\right)
$$

The second form arising from the application of the ideal gas law. It should be noted that at constant density the mean free path is temperature independent; and at constant pressure it is directly proportional to the temperature[10].

The quantity $\pi \sigma^{2}$, which appears in the denominator of the expression for the mean free path L, is the collision cross-section for the rigid spherical molecule. This quantity, which appears in all the expressions for the transport coefficient, is the cross- section of the imaginary sphere surrounding a molecule into which the center of another molecule cannot penetrate.

In this simple kinetic theory the transport coefficients can be expressed in terms of the quantity L. Consequently viscosity, diffusion, and thermal conductivity are sometimes referred to as mean free path phenomena. However, in the more rigorous approach for real gases it is found that the mean free path $\mathrm{L}$ does not appear naturally in the derivation of the transport properties.

The amount of a quantity passing in a unit time through a surface is called the flux (flow) of this quantity. The flux is a scalar algebraic quantity. The sign of the flux is determined by the choice of a positive direction. The positive direction is usually chosen arbitrary [10].

The coefficient of ordinary diffusion is the flux of mass of species i due to a unit gradient in the mass density of $i$; the coefficient of viscosity is the flux of the y-component of the momentum resulting from a unit gradient in the ycomponent of the velocity; and the coefficient of thermal conductivity is the energy flux due to a unit temperature gradient. In all three cases the fluxes are in the same direction as the gradients, and this direction defines the coordinate $\mathrm{z}$. The flux of mass of species $i$ is denoted by $\mathrm{j}_{\mathrm{iz}}$. The flux in the (z)-direction of the $y$-component of the momentum is $\mathrm{P}_{\mathrm{yz}}=\mathrm{P}_{\mathrm{zy}}$, where $\mathrm{p}$ is the pressure tensor. The flux of energy is denoted by $\mathrm{q}_{\mathrm{z}}$. Because of their physical similarity these three phenomena may be described by a common mathematical formalism. We therefore use the symbol $\Psi p$ to represent the z-component of any one of the three fluxes; the fluxes of mass of species i, the flux of the momentum in the 
(y)-direction, and the flux of energy. The symbol $\mathrm{P}$ represents correspondingly the mass density of species $i$, the momentum density, or the energy density. Let us consider the net flux in the $(+\mathrm{z})$-direction of the property associated with $\mathrm{P}$ (that is, the mass density of molecules of species $i$, the momentum density in the y-direction, or the energy density) through the plane O. Molecules approaching $\mathrm{O}$ from below have suffered their last collision at a distance $\mathrm{L}$ below plane $\mathrm{O}$. That is, they have come from plane $\mathrm{A}$ and have the values of the properties $\mathrm{P}_{\mathrm{A}}$ characteristic of that location. Similarly, molecules arriving at plane $\mathrm{O}$ from above have come from plane $\mathrm{B}$, and possess the values of properties $\mathrm{P}_{\mathrm{B}}$, characteristic of that plane. If the property $\mathrm{P}$ has the value $\mathrm{P}_{\mathrm{o}}$ at plane $\mathrm{O}$, as shown in Fig.(1), then one may write [7]:

$$
\mathrm{P}_{\mathrm{A}}=\mathrm{P}_{\mathrm{o}}-\mathrm{L}(\mathrm{dP} / \mathrm{dz}) ; \quad \mathrm{P}_{\mathrm{B}}=\mathrm{P}_{\mathrm{o}}+\mathrm{L}(\mathrm{dP} / \mathrm{dz})
$$

To the approximation that the gradient in the property $\mathrm{P}$ is constant over distances of the order of magnitude of a mean free path.

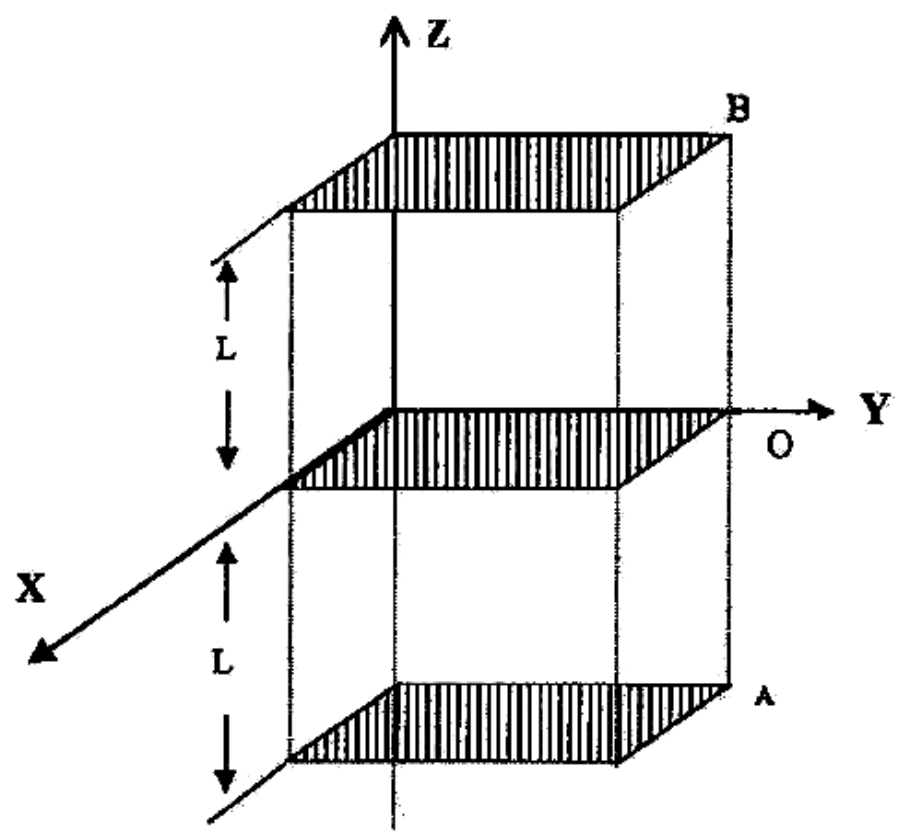

Fig. (1) : Molecular property gradient

In the case of diffusion, $P=N_{i}$ the concentration of species $i$. The value of $\mathrm{N}_{\mathrm{i}}$ is different at each of the planes $\mathrm{A}, \mathrm{O}, \mathrm{B}$, and a transfer of mass results. To consider viscosity, we imagine that the molecules at the plane A are moving in 
the (-y)-direction, that those at plane $\mathrm{O}$ are stationary, and that those at plane $\mathrm{B}$ are moving in the $(+y)$-direction.

Hence there is established a gradient in the y-component of the momentum, $\mathrm{P}=\mathrm{Nmv}_{\mathrm{y}}$. In the discussion of thermal conductivity, the planes $\mathrm{A}$, $\mathrm{O}$, and $\mathrm{B}$ are taken to be at different temperatures, and the property $\mathrm{P}$ is taken to be the energy density $\mathrm{Nc}_{\mathrm{v}} \mathrm{T}$ (where $\mathrm{c}_{\mathrm{v}}$ is the specific heat per molecule).

The amount of the property $\mathrm{P}$ which crosses plane $\mathrm{O}$ per unit area per unit time (that is, the flux of $\mathrm{P}$ ) from below is (1/6) $\Omega \mathrm{P}_{\mathrm{A}}$ the factor $1 / 6$ accounting for the fact that only one-sixth of the molecules at plane A move in the $(+\mathrm{z})-$ direction. Similarly the downward flux of $\mathrm{P}$ is $(1 / 6) \Omega \mathrm{P}_{\mathrm{B}}$. Hence the net flux, $\Psi_{\mathrm{P}}$, of the property $\mathrm{P}$ in the $(+\mathrm{z})$-direction across plane $\mathrm{O}$ is $[7,11]$

$$
\Psi_{\mathrm{P}}=\frac{1}{6} \Omega\left(\mathrm{P}_{\mathrm{A}}-\mathrm{P}_{\mathrm{B}}\right)=\frac{-1}{3} \Omega \mathrm{L}\left(\frac{\mathrm{dP}}{\mathrm{dz}}\right)=-\xi \frac{\sqrt{\pi \mathrm{mkT}}}{\mathrm{Nm} \pi \sigma^{2}}\left(\frac{\mathrm{dP}}{\mathrm{dz}}\right)
$$

In which the factor $\xi$ is $(2 / 3)$ when $\xi$ is taken to be $\sqrt{2}$. Specifically;

$$
\begin{aligned}
& \Psi_{\mathrm{N}_{\mathrm{i}}}=\mathrm{j}_{\mathrm{iz}}=-\frac{1}{3} \Omega \mathrm{L} \frac{\mathrm{dN_{ \textrm {i } }}}{\mathrm{dz}} \\
& \Psi_{\mathrm{Nmv}_{\mathrm{y}}}=\mathrm{p}_{\mathrm{yz}}=-\frac{1}{3} \Omega L N m \frac{\mathrm{dv}_{\mathrm{y}}}{\mathrm{dz}} \\
& \Psi_{\mathrm{Nc}_{\mathrm{v}} \mathrm{T}}=\mathrm{q}_{\mathrm{z}}=-\frac{1}{3} \Omega L \mathrm{Lc}_{\mathrm{v}} \frac{\mathrm{dT}}{\mathrm{dz}}
\end{aligned}
$$

These are the fluxes of mass of species i, momentum, and energy, respectively. Where;

$\Omega$ : is the arithmetic mean speed;

$\mathrm{L}$ : is the mean free path;

$\mathrm{N}$ : is the number of molecule per unit volume; and

$\mathrm{C}_{\mathrm{v}}$ : is the specific heat per molecule.

The transport coefficients are defined in terms of the fluxes as follow $[7,10,11]$;

$$
\begin{aligned}
& \Psi_{\mathrm{N}_{\mathrm{i}}}=\mathrm{j}_{\mathrm{iz}}=-\mathrm{D} \frac{\mathrm{dN_{ \textrm {i } }}}{\mathrm{dz}} \\
& \Psi_{\mathrm{Nmv}_{\mathrm{y}}}=\mathrm{P}_{\mathrm{yz}}=-\eta \frac{\mathrm{dV} \mathrm{y}}{\mathrm{dz}} \\
& \Psi_{\mathrm{Nc}_{\mathrm{v}} \mathrm{T}}=\mathrm{q}_{\mathrm{z}}=-\chi \frac{\mathrm{dT}}{\mathrm{dz}}
\end{aligned}
$$

where;

$\mathrm{D}$ : is the coefficient of diffusion;

$\eta$ : is the coefficient of viscosity; and

$\chi$ : is the coefficient of thermal conductivity. 
When these three equations are compared with the three preceding equations, we find that $[7,12,13]$ :

$$
\begin{aligned}
& D=\frac{1}{3} \Omega L=\xi \frac{\sqrt{\pi m k T}}{\pi \sigma^{2}} \frac{1}{\rho}=\frac{\chi m}{\rho c_{v}} \\
& \eta=\frac{1}{3} \mathrm{Nm} \Omega L=\xi \frac{\sqrt{\pi \mathrm{mkT}}}{\pi \sigma^{2}}=\rho \mathrm{D} \\
& \chi=\frac{1}{3} \mathrm{Nc}_{\mathrm{V}} \Omega \mathrm{L}=\xi \frac{\sqrt{\pi \mathrm{mkT}}}{\pi \sigma^{2}} \frac{\mathrm{c}_{U}}{\mathrm{~m}}=\frac{\mathrm{c}_{\mathrm{v}} \eta}{\mathrm{m}}
\end{aligned}
$$

In which $\rho=\mathrm{Nm}=\mathrm{pm} / \mathrm{kT}$ is the density of the gas. The application of the rigorous kinetic theory to the rigid-sphere model gives exactly the above form for the transport coefficients. The rigorous theory for rigid-sphere molecules, however, predicts that the values of $\xi$ are different for the various fluxes as follow [7];

$$
\begin{array}{ll}
\xi_{\mathrm{D}}=\frac{3}{8} & \frac{\eta}{\rho \mathrm{D}}=\frac{5}{6} \\
\xi_{\eta}=\frac{5}{16} & \frac{\eta \mathrm{c}_{v}}{\chi \mathrm{m}}=\frac{2}{5} \\
\xi_{\chi}=\frac{25}{32} & \frac{\rho \mathrm{Dc_{v }}}{\chi \mathrm{m}}=\frac{12}{25}
\end{array}
$$

Inserting these values into Eqns.12, 13, and 14 we may rewrite the expressions for the transport coefficients in practical units [7]:

$$
\begin{array}{ll}
D=2.6280 \times 10^{-3} \frac{\sqrt{T^{3} / M}}{P_{r} \sigma^{2}} & \mathrm{~cm}^{2} / \mathrm{sec} \\
\eta=2.6693 \times 10^{-5} \frac{\sqrt{\mathrm{MT}}}{\sigma^{2}} & \mathrm{gm} / \mathrm{cm} \mathrm{sec} \\
\chi=1.9891 \times 10^{-4} \frac{\sqrt{\mathrm{T} / \mathrm{M}}}{\sigma^{2}}=\frac{15}{4} \frac{\mathrm{R}}{\mathrm{M}} \eta & \mathrm{cal} / \mathrm{cm} \mathrm{deg} \mathrm{sec}
\end{array}
$$

where;

M: molecular weight;

$\mathrm{T}$ : temperature in $\mathrm{K}$;

$\mathrm{P}_{\mathrm{r}}$ : pressure in atmospheres; and

$\sigma:$ molecular diameter in $\mathrm{A}^{\circ}$. 


\section{Experiment:}

The transport parameters (the diffusion coefficient $\mathrm{D}$, the viscosity coefficient $\eta$ and the thermal conductivity coefficient $\chi$ ) are studied as a function of gas pressure $\mathrm{p}$ and gas temperature $\mathrm{T}$ by the experimental technique described in details in literature [14].

\section{Results and Discussion:}

\section{1:. Pressure Dependence}

\subsubsection{Diffusion Coefficient $D_{T, \lambda}(P)$}

Figure (2) shows the dependence of the diffusion Coefficient D of $\mathrm{CO}_{2}$ gas on its pressure $p_{r}$ at constant temperature $T$ and the incidence laser light wavelength $\lambda$.

From that figure, the diffusion coefficient $\mathrm{D}$ of $\mathrm{CO}_{2}$ gas was inversely proportional to its pressure $\mathrm{p}_{\mathrm{r}}$. This result also predicted by the inverse relation between the diffusion coefficient $\mathrm{D}$ and the pressure $\mathrm{p}_{\mathrm{r}}$ which we have mentioned Eqn.16.

At constant temperature $\mathrm{T}$, by increasing the pressure $\mathrm{p}_{\mathrm{r}}$, the mean free path $\mathrm{L}$ of the gas decreases according to equation(2). Also, the diffusion coefficient $\mathrm{D}$ was directly proportional to the mean free path $\mathrm{L}$, so that, the diffusion coefficient of carbon dioxide gas decreases by increasing the pressure $\mathrm{p}_{\mathrm{r}}$ at constant temperature $\mathrm{T}$.

Rate of change of diffusion coefficient $\mathrm{D}$ of $\mathrm{CO}_{2}$-gas was estimated to be $\left(\mathrm{dD} / \mathrm{dp}_{\mathrm{r}}\right)_{\mathrm{T}, \lambda}$ within $\mathrm{CO}_{2}$-pressure ranging from $60-90 \mathrm{~cm} . \mathrm{Hg}$ and $\mathrm{CO}_{2^{-}}$ temperature was fixed at $\mathrm{T}=308,313,318,323,328,333,338,343,348,353$, and $358 \mathrm{~K}$. The incident laser wavelength $\lambda$ was selected to be $\lambda=476,488,502$, and $514.5 \mathrm{~nm}$. The values of $\left(\mathrm{dD} / \mathrm{dp}_{\mathrm{r}}\right)_{\mathrm{T}, \lambda}$ were given in Table (1). 


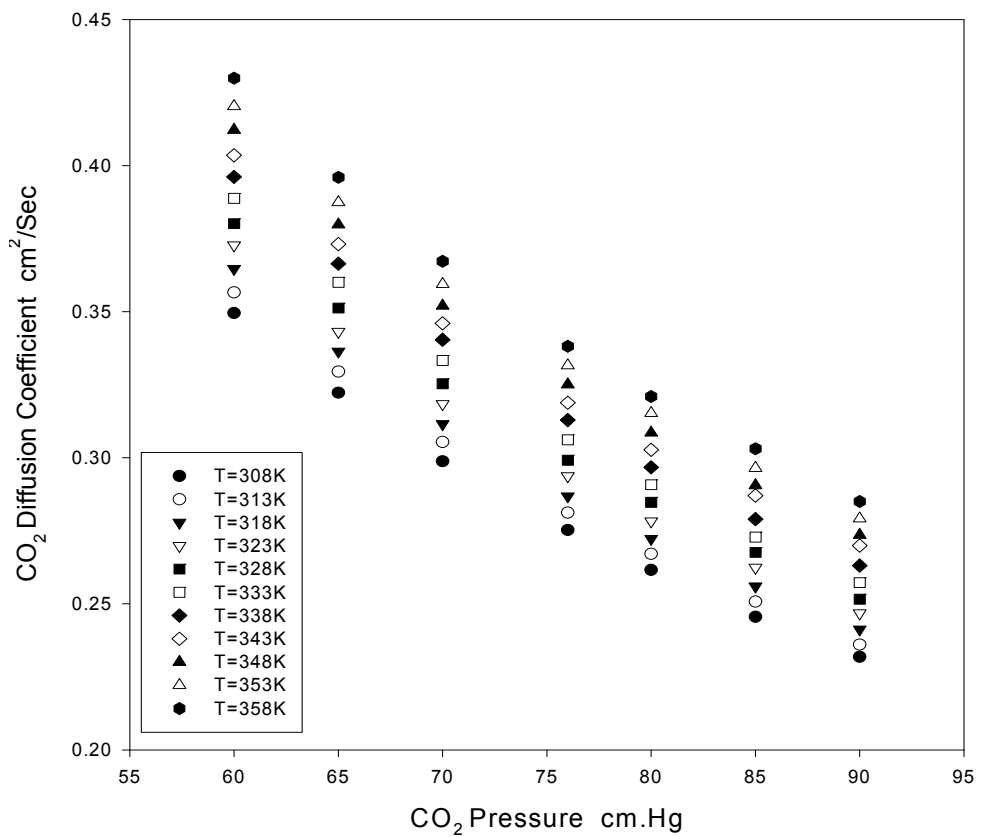

Fig. (2): Pressure dependence of $\mathrm{CO}_{2-}$ diffusion coefficient at constant $\mathrm{CO}_{2-}$ temperature and laser wavelength, $\lambda=488 \mathrm{~nm}$.

Table (1): Rate of change of $\mathrm{CO}_{2}$-diffusion coefficient with respect to $\mathrm{CO}_{2}$ pressure $(60-90 \mathrm{~cm} . \mathrm{Hg})$ at constant $\mathrm{CO}_{2}$-temperature and laser wavelength $(\lambda=488 \mathrm{~nm})$.

\begin{tabular}{|c|c|c|c|c|}
\hline $\begin{array}{c}\text { Temperature } \\
\mathrm{T}, \mathrm{K}\end{array}$ & $\begin{array}{c}\left(\mathrm{dD} / \mathrm{dp}_{\mathrm{r}}\right)_{\mathrm{T}, 476} \\
\mathrm{x}-10^{-3}\end{array}$ & $\begin{array}{c}\left(\mathrm{dD}^{-} \mathrm{dp}_{\mathrm{r}}\right)_{\mathrm{T}, 488} \\
\mathrm{x}-10^{-3}\end{array}$ & $\begin{array}{c}\left(\mathrm{dD} / \mathrm{dp}_{\mathrm{r}}\right)_{\mathrm{T}, 502} \\
\mathrm{x}-10^{-3}\end{array}$ & $\begin{array}{c}\left(\mathrm{dD} / \mathrm{dp}_{\mathrm{r}}\right)_{\mathrm{T}, 514.5} \\
\mathrm{x}-10^{-3}\end{array}$ \\
\hline 308 & 1.42 & 1.43 & 1.42 & 1.42 \\
\hline 313 & 1.45 & 1.46 & 1.44 & 1.45 \\
\hline 318 & 1.47 & 1.48 & 1.48 & 1.47 \\
\hline 323 & 1.49 & 1.51 & 1.50 & 1.50 \\
\hline 328 & 1.51 & 1.54 & 1.52 & 1.53 \\
\hline 333 & 1.53 & 1.58 & 1.55 & 1.56 \\
\hline 338 & 1.55 & 1.60 & 1.58 & 1.59 \\
\hline 343 & 1.58 & 1.63 & 1.62 & 1.63 \\
\hline 348 & 1.63 & 1.64 & 1.65 & 1.66 \\
\hline 353 & 1.65 & 1.66 & 1.68 & 1.69 \\
\hline 358 & 1.68 & 1.70 & 1.71 & 1.71 \\
\hline
\end{tabular}




\subsection{Viscosity Coefficient $\eta_{T, \lambda}\left(p_{r}\right)$ :}

Figure (3) shows the dependence of the viscosity coefficient $\eta$ of carbon dioxide gas on its pressure $p_{r}$ at constant temperature T. From that figure one could deduce that, the viscosity coefficient $\eta$ of $\mathrm{CO}_{2}$-gas has a steady decrease with $\mathrm{CO}_{2}$-pressure for $\mathrm{T}=308,313,318 \mathrm{~K}$ while for temperature $\mathrm{T}>318 \mathrm{~K}$ was a wavy variation. The rate of change $\left(d \eta / d p_{r}\right)_{T, \lambda}$ was given in Table (2). Although Eqn.17 shows that the coefficient of viscosity $\eta$ does not depend on the pressure $\mathrm{p}_{\mathrm{r}}$ while the temperature $\mathrm{T}$ of the gas is constant. Among the quantities in that equation, only the number of molecules in a unit volume $\mathrm{N}$ and the mean free path $\mathrm{L}$ depend on the pressure $\mathrm{p}_{\mathrm{r}}$. But the number of molecules in a unit volume $\mathrm{N}$ was directly proportional to the pressure $\mathrm{p}_{\mathrm{r}}$ and the mean free path $\mathrm{L}$ is inversely proportional to the pressure $\mathrm{p}_{\mathrm{r}}$ of the gas. This leads, practically, to the important conclusion that the viscosity coefficient $\eta$ of gases depends slightly on the pressure $\mathrm{p}_{\mathrm{r}}$ of the gas.

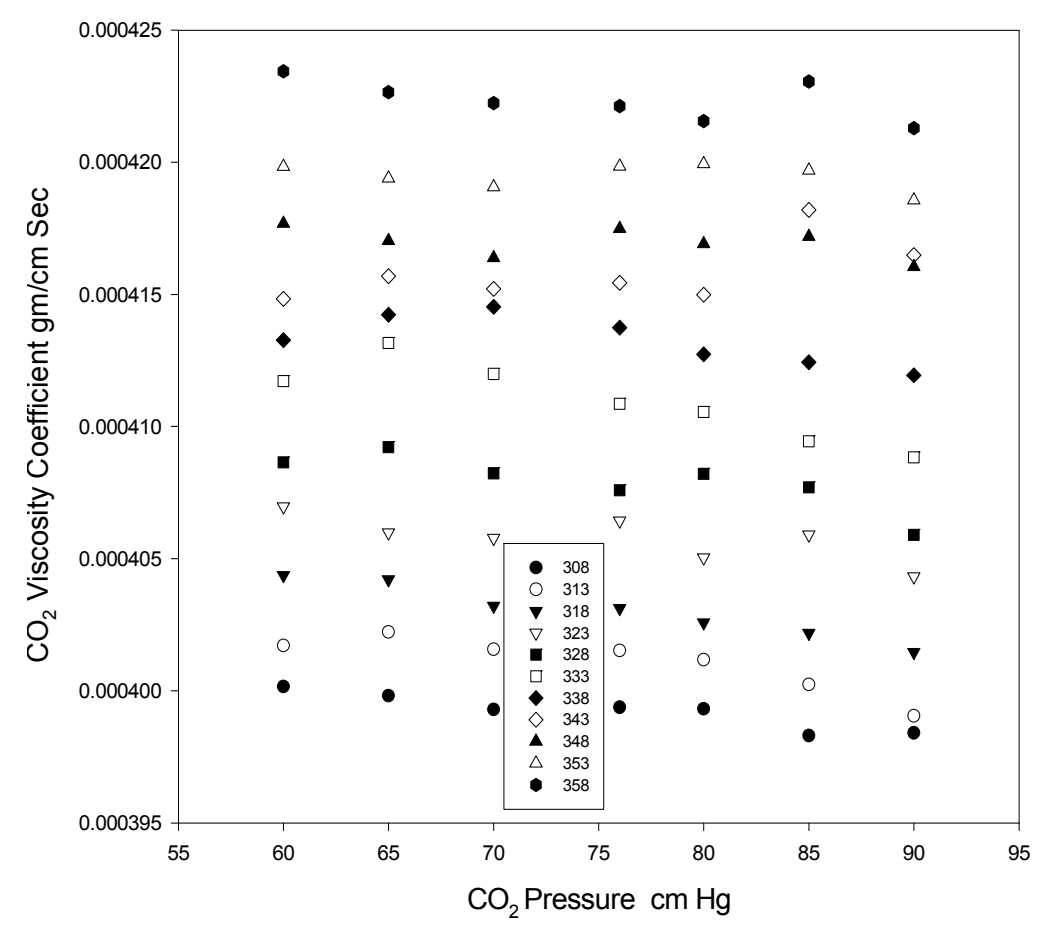

Fig. (3): Pressure dependence of $\mathrm{CO}_{2}$ - viscosity coefficient at constant $\mathrm{CO}_{2}$-temperature and laser wavelength, $\lambda=488 \mathrm{~nm}$. 
Table (2): Rate of change of $\mathrm{CO}_{2}$-viscosity coefficient with respect to $\mathrm{CO}_{2-}$ pressure $(60-90 \mathrm{~cm} . \mathrm{Hg})$ at constant $\mathrm{CO}_{2}$-temperature and laser wavelength.

\begin{tabular}{|c|c|c|c|c|}
\hline $\begin{array}{c}\text { Temperature } \\
\mathrm{K}\end{array}$ & $\begin{array}{c}\left(\mathrm{d \eta} / \mathrm{dp}_{\mathrm{r}}\right)_{\mathrm{T}, 476} \\
\mathrm{x}-10^{-8}\end{array}$ & $\begin{array}{c}\left(\mathrm{d \eta} / \mathrm{dp}_{\mathrm{r}}\right)_{-, 488} \\
{\mathrm{x}-10^{-7}}^{-}\end{array}$ & $\begin{array}{c}\left(\mathrm{d \eta} / \mathrm{dp}_{\mathrm{r}}\right)_{\mathrm{T}, 502} \\
\mathrm{x}-10^{-8}\end{array}$ & $\begin{array}{c}\left(\mathrm{d \eta} / \mathrm{dp}_{\mathrm{r}}\right)_{\mathrm{T}, 514.5} \\
\mathrm{x}-10^{-9}\end{array}$ \\
\hline 308 & 2.89 & 1.31 & 2.16 & 3.67 \\
\hline 313 & 4.46 & 1.28 & 2.37 & 4.87 \\
\hline 318 & 6.09 & 1.24 & 3.35 & 6.45 \\
\hline 323 & 9.15 & 1.05 & 4.63 & 7.84 \\
\hline 328 & 12.23 & 0.98 & 4.44 & 7.98 \\
\hline 333 & 8.34 & 1.15 & 5.24 & 8.88 \\
\hline 338 & 3.72 & 1.39 & 13.19 & 22.35 \\
\hline 343 & 4.13 & 1.25 & 12.62 & 21.38 \\
\hline 348 & 4.53 & 1.34 & 11.05 & 18.71 \\
\hline 353 & 3.97 & 0.48 & 5.53 & 9.37 \\
\hline 358 & 1.64 & 0.18 & 3.67 & 6.22 \\
\hline
\end{tabular}

\subsection{Thermal Conductivity $\chi_{T, \lambda}\left(P_{r}\right)$}

Figure (4) shows the dependence of the thermal conductivity coefficient $\chi$ of $\mathrm{CO}_{2}$-gas on the pressure $\mathrm{p}_{\mathrm{r}}$ at constant temperature $\mathrm{T}$. From those figure, the thermal conductivity coefficient $\chi$ of $\mathrm{CO}_{2}$-gas depends slowly on the pressure $\mathrm{p}_{\mathrm{r}}$ while the temperature $\mathrm{T}$ of the gas was constant. The rate of change of $\mathrm{CO}_{2-}$ thermal conductivity with respect to $\mathrm{CO}_{2}$-pressure $\left(\mathrm{d} \chi / \mathrm{dP}_{\mathrm{r}}\right)_{\mathrm{T}, \lambda}$ was given in Table (3). From Eqn.18 it could be predicted how the coefficient of thermal conductivity $\chi$ should not depend on the pressure $\mathrm{p}_{\mathrm{r}}$ at constant gas temperature $\mathrm{T}$ in case of the molecular diameter $\sigma$ was constant.

Like the viscosity coefficient, among the quantities in Eqn.18, only the number of molecules in a unit volume $\mathrm{N}$ and the mean free path $\mathrm{L}$ depend on the pressure $p_{r}$. But the first of these quantities was directly proportional and the second was inversely proportional to the pressure $\mathrm{p}_{\mathrm{r}}$ of the gas. As a practical conclusion the coefficient of thermal conductivity $\chi$ of gases has a weak dependence on the pressure $\mathrm{p}_{\mathrm{r}}$ of the gas at constant temperature $\mathrm{T}$.

This holds only as long as $\mathrm{L}$ remains small in comparison with the size of the gap through which the gas was flowing (in comparison with the diameter of the gas sample cell). Regarding less of this condition, the thermal conductivity coefficient being to depend more and more on the pressure, diminishing when the latter drops. 


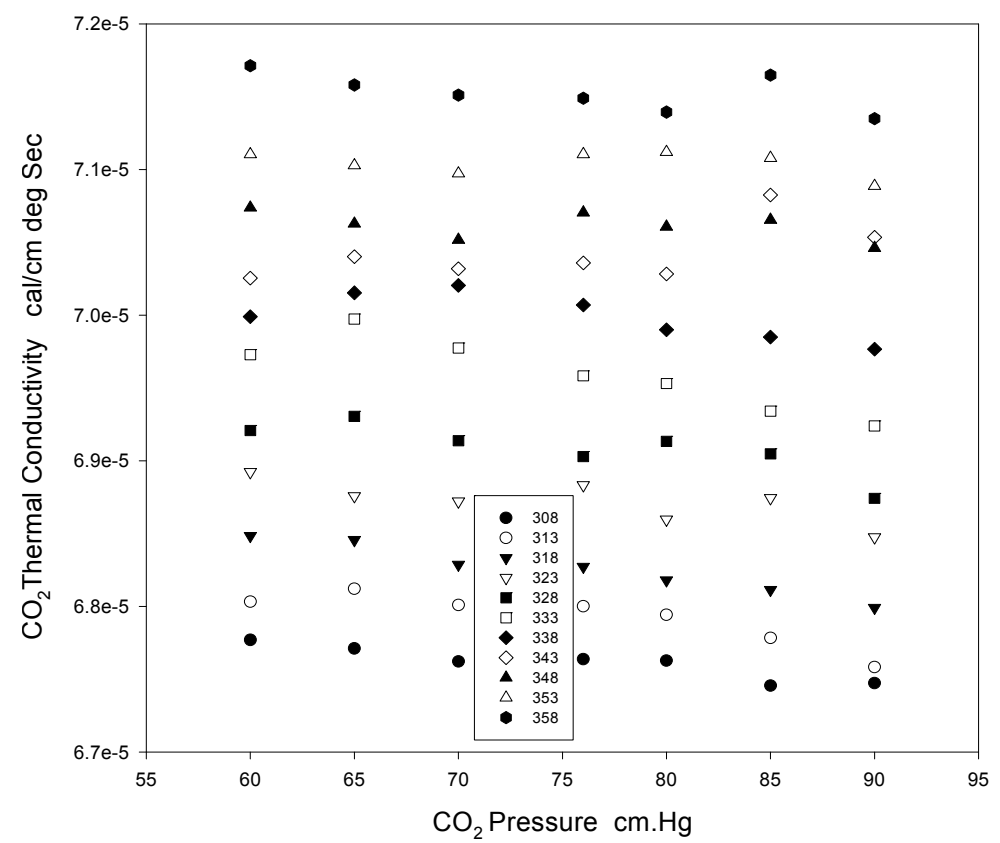

Fig. (4): Pressure dependence of $\mathrm{CO}_{2}$-thermal conductivity coefficient at constant $\mathrm{CO}_{2}$ temperature and laser wavelength, $\lambda=488 \mathrm{~nm}$.

Table (3): Rate of change of $\mathrm{CO}_{2}$-thermal conductivity with respect to $\mathrm{CO}_{2}$ pressure $(60-90 \mathrm{~cm} . \mathrm{Hg})$ at constant $\mathrm{CO}_{2}$-temperature and laser wavelength.

\begin{tabular}{|c|c|c|c|c|}
\hline $\begin{array}{c}\text { Temperature } \\
\mathrm{K}\end{array}$ & $\begin{array}{c}\left(\mathrm{d} \chi / \mathrm{dp}_{\mathrm{r}}\right)_{\mathrm{T}, 476} \\
\mathrm{x}-10^{-8}\end{array}$ & $\begin{array}{c}\left(\mathrm{d} \chi / \mathrm{dp}_{\mathrm{r}}\right)_{\mathrm{T}, 488} \\
\mathrm{x}-10^{-8}\end{array}$ & $\begin{array}{c}\left(\mathrm{d} \chi / \mathrm{dp}_{\mathrm{r}}\right)_{\mathrm{T}, 502} \\
\mathrm{x}-10^{-8}\end{array}$ & $\begin{array}{c}\left(\mathrm{d} \chi / \mathrm{dp}_{\mathrm{r}}\right)_{\mathrm{T}, 514.5} \\
\mathrm{x}-10^{-8}\end{array}$ \\
\hline 308 & 0.489 & 0.992 & 0.367 & 1.01 \\
\hline 313 & 0.876 & 1.25 & 0.268 & 1.03 \\
\hline 318 & 1.03 & 1.48 & 0.167 & 1.05 \\
\hline 323 & 1.55 & 1.62 & 0.785 & 0.970 \\
\hline 328 & 2.07 & 1.05 & 0.430 & 0.0611 \\
\hline 333 & 1.41 & 1.37 & 0.888 & 0.475 \\
\hline 338 & 6.30 & 2.12 & 3.234 & 0.844 \\
\hline 343 & 0.70 & 1.12 & 2.14 & 1.95 \\
\hline 348 & 0.046 & 1.17 & 1.87 & 1.06 \\
\hline 353 & 1.39 & 4.78 & 0.937 & 1.31 \\
\hline 358 & 0.278 & 0.227 & 0.622 & 0.751 \\
\hline
\end{tabular}




\section{Temperature Dependence}

\subsection{Diffusion Coefficient $D_{p, \lambda}(T)$}

The dependence of the diffusion coefficient $\mathrm{D}$ of $\mathrm{CO}_{2}$-gas on its temperature $\mathrm{T}$ at constant $\mathrm{CO}_{2}$-pressure $\mathrm{p}_{\mathrm{r}}$ and wavelength $\lambda$ was shown in Fig.(5). The temperature of $\mathrm{CO}_{2}$-gas with the sample's cell was changing between 308 and $358 \mathrm{~K}$ where its pressure was fixed at $\mathrm{p}_{\mathrm{r}}=60,65,70,76,80,85$, $90 \mathrm{~cm} . \mathrm{Hg}$. The laser wavelength was selected to be with the same mentioned values.

It was noted from those figure that, the diffusion coefficient $\mathrm{D}$ of $\mathrm{CO}_{2}$-gas was directly proportional to the temperature $T$ at constant pressure $p_{r}$ and wavelength $\lambda$. Also, it was predicted from Eqn.16 which showed a direct relation between diffusion coefficient $\mathrm{D}$ and temperature $\mathrm{T}$.

It could be conclude that at constant pressure $\mathrm{p}_{\mathrm{r}}$, the mean free path $\mathrm{L}$ of the gas increases by increasing its temperature $\mathrm{T}$, from the same equation, and the diffusion coefficient $\mathrm{D}$ was directly proportional to the mean free path $\mathrm{L}$, so that, the diffusion coefficient $\mathrm{D}$ of carbon dioxide gas increases by increasing the temperature $T$ at constant pressure $\mathrm{p}_{\mathrm{r}}$.

Table (4) gave the estimated values of $(\mathrm{dD} / \mathrm{dT})_{\mathrm{p}, \lambda}$ on which were obtained with the aid of Fig.(5).

\subsection{Viscosity Coefficient $\eta_{p, \lambda}(T)$}

The dependence of the viscosity coefficient $\eta$ of $\mathrm{CO}_{2}$-gas on the temperature $\mathrm{T}$ at constant pressure $\mathrm{p}_{\mathrm{r}}$ was shown graphically in Fig.(6). From which the viscosity coefficient $\eta$ of $\mathrm{CO}_{2}$ increases by increasing its temperature $\mathrm{T}$. The obtained experimental results were in a good agreement with the Eqn.17 from which the viscosity coefficient $\eta$ was obtained.

Equation 17 included the mean velocity of the thermal movements of the molecules $\Omega$, which depends on the temperature T, proportional to its square root. Hence, the viscosity coefficient should also grow with increasing temperature $\mathrm{T}$ in proportional to $(\mathrm{T})^{1 / 2}$ which was acceptable theoretically. Also, by increasing the temperature $\mathrm{T}$ the mean free path $\mathrm{L}$ increases, this also leads the viscosity coefficient $\eta$ of the carbon dioxide gas increases by increasing its temperature $\mathrm{T}$.

The rate of change of viscosity coefficient $\eta$ of the carbon dioxide gas, $(\mathrm{d} \eta / \mathrm{dT})_{\mathrm{p}, \lambda}$, was evaluated from Fig.(5) with the values given in Table (5) for selected laser wavelength. 


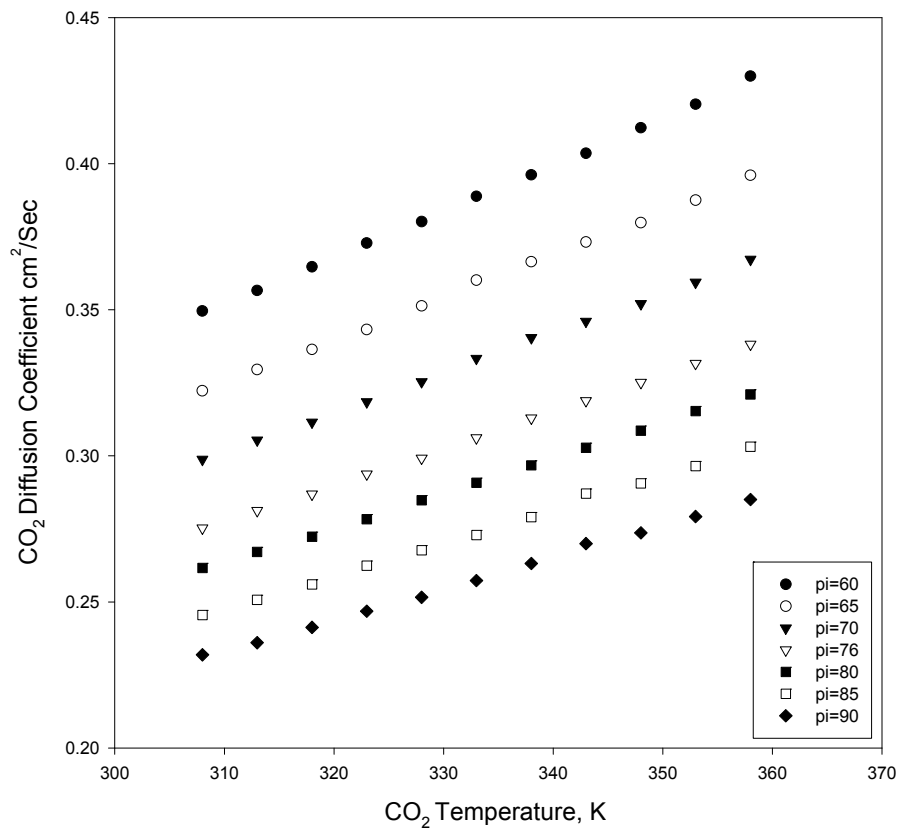

Fig. (5): Temperature dependence of $\mathrm{CO}_{2^{-}}$diffusion coefficient at constant $\mathrm{CO}_{2^{-}}$ pressure and laser wavelength, $\lambda=488 \mathrm{~nm}$.

Table (4): Rate of change of CO2-diffusion coefficient with respect to $\mathrm{CO} 2$ temperature $(308-358 \mathrm{~K})$ at constant $\mathrm{CO} 2$-pressure and laser wavelength.

\begin{tabular}{|c|c|c|c|c|}
\hline $\begin{array}{c}\text { Pressure, } \\
\mathrm{cm} . \mathrm{Hg}\end{array}$ & $\begin{array}{c}(\mathrm{dD} / \mathrm{dT})_{\mathrm{p}, 476} \\
\mathrm{x}-10^{-3}\end{array}$ & $\begin{array}{c}(\mathrm{dD} / \mathrm{dT})_{\mathrm{p}, 488} \\
\mathrm{x}-10^{-3}\end{array}$ & $\begin{array}{c}(\mathrm{dD} / \mathrm{dT})_{\mathrm{p}, 502} \\
\mathrm{x}-10^{-3}\end{array}$ & $\begin{array}{c}(\mathrm{dD} / \mathrm{dT})_{\mathrm{p}, 514.5} \\
\mathrm{x}-10^{-3}\end{array}$ \\
\hline 60 & 1.65 & 1.59 & 1.71 & 1.85 \\
\hline 65 & 1.54 & 1.47 & 1.58 & 1.68 \\
\hline 70 & 1.42 & 1.36 & 1.48 & 1.56 \\
\hline 76 & 1.33 & 1.26 & 1.37 & 1.44 \\
\hline 80 & 1.27 & 1.20 & 1.29 & 1.38 \\
\hline 85 & 1.19 & 1.16 & 1.20 & 1.31 \\
\hline 90 & 1.11 & 1.08 & 1.12 & 1.22 \\
\hline
\end{tabular}




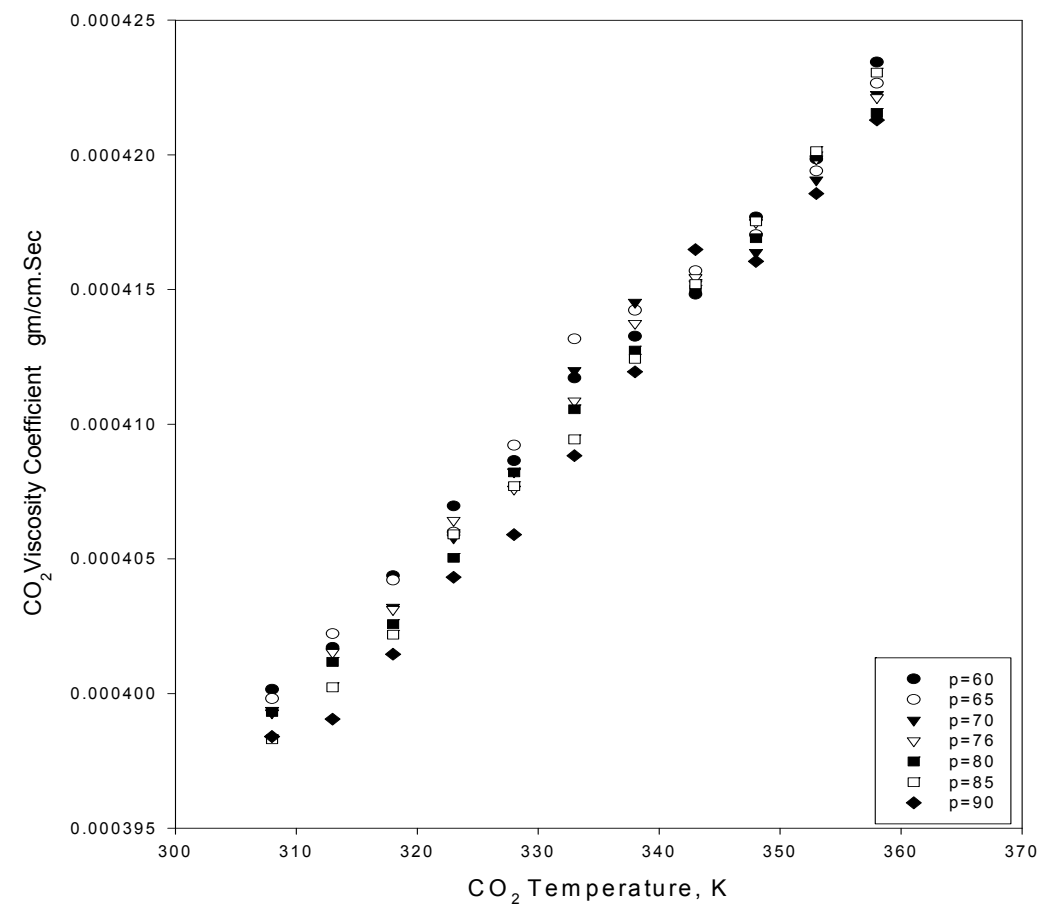

Fig. (6): Temperature dependence of $\mathrm{CO}_{2^{-}}$viscosity coefficient at constant $\mathrm{CO}_{2^{-}}$ pressure and laser wavelength, $\lambda=488 \mathrm{~nm}$.

Table (5): Rate of change of $\mathrm{CO}_{2}$-viscosity coefficient with respect to $\mathrm{CO}_{2}$ temperature $(308-358 \mathrm{~K})$ at constant $\mathrm{CO}_{2}$-pressure and laser wavelength.

\begin{tabular}{|c|c|c|c|c|}
\hline $\begin{array}{c}\text { Pressure, } \\
\mathrm{cm} . \mathrm{Hg}\end{array}$ & $\begin{array}{c}(\mathrm{d \eta} / \mathrm{dT})_{\mathrm{p}, 476} \\
\times 10^{-7}\end{array}$ & $\begin{array}{c}(\mathrm{d} \eta / \mathrm{dT})_{\mathrm{p}, 488} \\
\times 10^{-7}\end{array}$ & $\begin{array}{c}(\mathrm{d \eta} / \mathrm{dT})_{\mathrm{p}, 502} \\
\times 10^{-7}\end{array}$ & $\begin{array}{c}(\mathrm{d \eta} / \mathrm{dT})_{\mathrm{p}, 514.5} \\
\times 10^{-7}\end{array}$ \\
\hline 60 & 5.21 & 4.53 & 5.46 & 6.76 \\
\hline 65 & 5.38 & 4.47 & 5.47 & 6.39 \\
\hline 70 & 5.34 & 4.54 & 5.67 & 6.45 \\
\hline 76 & 5.61 & 4.62 & 5.66 & 6.49 \\
\hline 80 & 5.69 & 4.61 & 5.52 & 6.70 \\
\hline 85 & 5.61 & 4.96 & 5.30 & 6.74 \\
\hline 90 & 5.60 & 4.85 & 5.11 & 6.53 \\
\hline
\end{tabular}




\subsection{Thermal Conductivity $\chi_{\mathrm{p}, \mathrm{\lambda}}(\mathrm{T})$}

The thermal conductivity coefficient $\chi$ of carbon dioxide $\mathrm{CO}_{2}$-gas as a function of the temperature $\mathrm{T}$ at constant pressure $\mathrm{p}_{\mathrm{r}}$ and constant wavelength $\lambda$ was shown in Fig. (7). From that figure, its noted that the thermal conductivity coefficient $\chi$ of carbon dioxide gas increases by increasing $\mathrm{CO}_{2}$ temperature $\mathrm{T}$ while the pressure $p_{r}$ of the gas was constant in agreement with the Eqn.18 of the thermal conductivity coefficient $\chi$.

Since Eqn.18 includes the mean velocity of the thermal movements of the molecules $\Omega$, which depends on the temperature $\mathrm{T}$, and proportional to its square root. Therefore, the thermal conductivity coefficient $\chi$ should also increase with increasing temperature $\mathrm{T}$.

In addition, by increasing the temperature $\mathrm{T}$ the mean free path $\mathrm{L}$ will increase, which leads to the thermal conductivity coefficient $\chi$ of gases increases by increasing its temperature $\mathrm{T}$. This rate of increment $(\mathrm{d} \chi / \mathrm{dT})_{\mathrm{p}, \lambda}$ was calculated from Fig.(7) with the values given in Table (6).

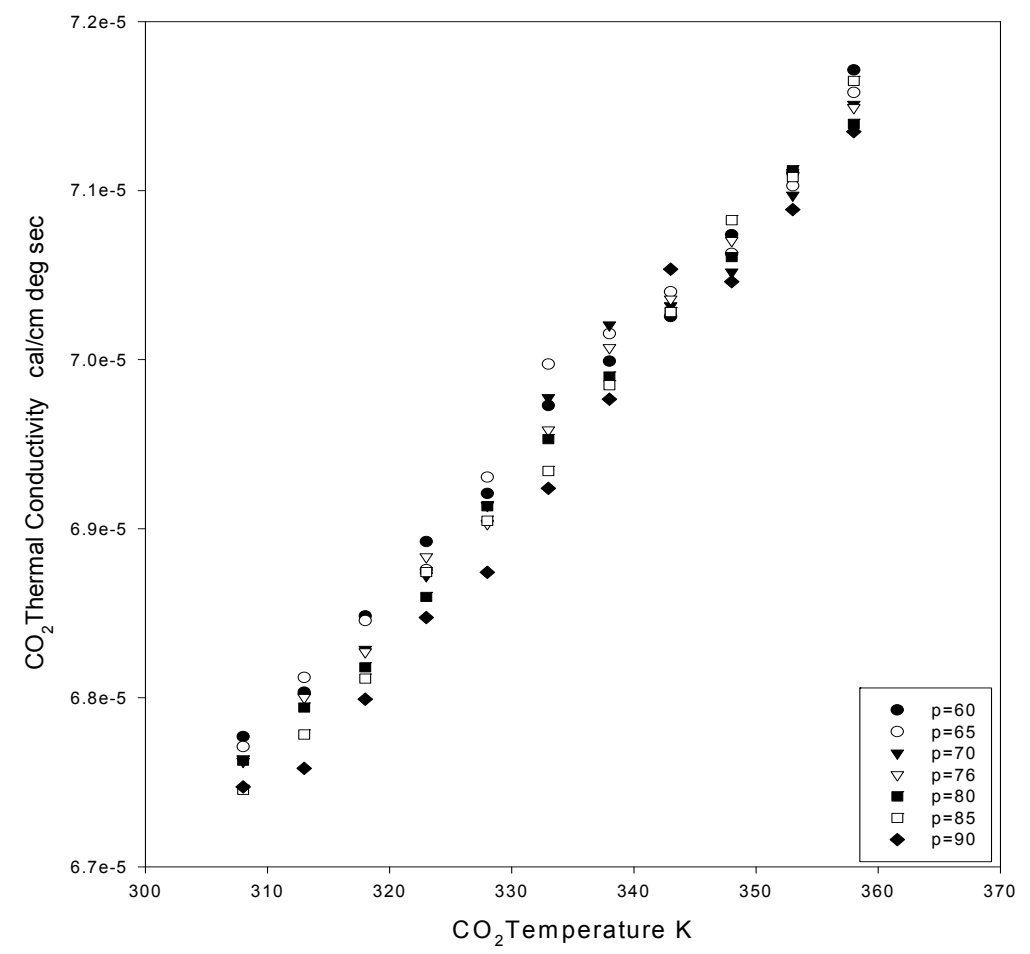

Fig. (7): Temperature dependence of $\mathrm{CO}_{2}$ - thermal conductivity coefficient at constant $\mathrm{CO}_{2}$-pressure and laser wavelength, $\lambda=488 \mathrm{~nm}$. 


\section{Conclusion:}

Table 7 shows some of the evaluated values of the refractive index and the transport coefficients for carbon dioxide $\left(\mathrm{CO}_{2}\right)$ gas compared with literature values $[15,16]$.

From this table, one can note that the refractive index measurement was in a good agreement with literature value. The value of the transport coefficients gives an indication of the inadequacy of the rigid sphere model. This result gives only the approximate pressure and temperature dependence for real $\mathrm{CO}_{2}$ gas, since the true temperature dependence must includes the effect of the interaction, which takes place between real molecules.

Table (6): Rate of change of CO2-thermal conductivity coefficient with respect to $\mathrm{CO} 2$-temperature $(308-358 \mathrm{~K})$ at constant $\mathrm{CO} 2$-pressure and laser wavelength.

\begin{tabular}{|c|c|c|c|c|}
\hline $\begin{array}{c}\text { Pressure, } \\
\mathrm{cm} . \mathrm{Hg}\end{array}$ & $\begin{array}{c}(\mathrm{d} \chi / \mathrm{dT})_{\mathrm{p}, 476} \\
\times 10^{-8}\end{array}$ & $\begin{array}{c}(\mathrm{d} \chi / \mathrm{dT})_{\mathrm{p}, 488} \\
\times 10^{-8}\end{array}$ & $\begin{array}{c}(\mathrm{d} \chi / \mathrm{dT})_{\mathrm{p}, 502} \\
\times 10^{-8}\end{array}$ & $\begin{array}{c}(\mathrm{d} \chi / \mathrm{dT})_{\mathrm{p}, 514.5} \\
\times 10^{-7}\end{array}$ \\
\hline 60 & 8.82 & 7.67 & 9.24 & 1.14 \\
\hline 65 & 9.10 & 7.57 & 9.26 & 1.08 \\
\hline 70 & 9.04 & 7.68 & 9.60 & 1.09 \\
\hline 76 & 9.50 & 7.83 & 9.58 & 1.10 \\
\hline 80 & 9.64 & 7.81 & 9.35 & 1.13 \\
\hline 85 & 9.50 & 8.39 & 8.97 & 1.14 \\
\hline 90 & 9.49 & 8.21 & 8.65 & 1.11 \\
\hline
\end{tabular}

Table (7): Comparison between the measured and literature values of refractive index and transport coefficients of Carbon Dioxide gas.

\begin{tabular}{|c|c|c|}
\hline Parameter & Measured value & Literature value[21] \\
\hline Refractive index & $\begin{array}{c}1.000406 \\
\mathrm{~T}=308 \mathrm{~K}, \mathrm{p}_{\mathrm{r}}=1 \mathrm{~atm} \\
\lambda=488 \mathrm{~nm}\end{array}$ & $\begin{array}{c}1.000449 \text { to } 1.000450 \\
\mathrm{~T}=273 \mathrm{~K}, \mathrm{p}_{\mathrm{r}}=1 \mathrm{~atm} \\
\text { white light }\end{array}$ \\
\hline $\begin{array}{c}\text { Diffusion coefficient } \\
\mathrm{cm}^{2} / \mathrm{sec}\end{array}$ & $\begin{array}{c}0.275 \\
\mathrm{~T}=308 \mathrm{~K}, \mathrm{p}_{\mathrm{r}}=1 \mathrm{~atm}\end{array}$ & $\begin{array}{c}0.202 \\
\mathrm{~T}=307.3 \mathrm{~K}, \mathrm{p}_{\mathrm{r}}=1 \mathrm{~atm}\end{array}$ \\
\hline $\begin{array}{c}\text { Viscosity coefficient } \\
\text { gm/cm.sec }\end{array}$ & $\begin{array}{c}33.9 \times 10^{-5} \\
\mathrm{~T}=308 \mathrm{~K}, \mathrm{p}_{\mathrm{r}}=1 \mathrm{~atm}\end{array}$ & $\begin{array}{c}\mathrm{T}=308.6 \times 10^{-5} \\
\mathrm{~K}, \mathrm{p}_{\mathrm{r}}=1 \mathrm{~atm}\end{array}$ \\
\hline $\begin{array}{c}\text { Thermal conductivity } \\
\text { Cal/deg.cm.sec }\end{array}$ & $67.6 \times 10^{-6}$ & $41.74 \times 10^{-6}$ \\
$\mathrm{~T}=308 \mathrm{~K}, \mathrm{p}_{\mathrm{r}}=1 \mathrm{~atm}$ & $\mathrm{~T}=310.8 \mathrm{~K}, \mathrm{p}_{\mathrm{r}}=1 \mathrm{~atm}$ \\
\hline
\end{tabular}




\section{References}

1. Braga ALF, Zanobetti A, and Schwartz J. Epidemiology, 12, 62(2001).

2. Kunst AE, Looman CW, Mackenbach JP. Am, J Epidemiology 137, 331(1993).

3. Saez M, Sunyer J, Castellsague J, Murillo C, and Anto JM. Int J Epidemiol 24, 576 (1995).

4. Katsouyanni K, Pantazopoulou A, Touloumi G, Tselepidaki I, Moustris K, and Asimakopoulos D, Arch Environ Health 48, 235 (1993).

5. IPCC, "Climate Change (1995), The Science of Climate Change." Cambridge, UK: Cambridge University Press (1996).

6. McMichael AJ, Ando M, Carcavallo R, Epstein P, Haines A, Jendritsky G, Climate Change and Human Health. Geneva: World Health Organization (1996).

7. Irschfelder JO, Curtiss CF, Bird RB "Molecular theory of gases and liquids" Copyright, USA (1954).

8. W.Sears FW, Salinger GL "Thermodynamics, Kinetic Theory, and Statistical Thermodynamics" Addison-Wesely Publishing Company, Inc, 3rd edition (1975).

9. Ragone DV "Thermodynamics of Materials" copyright by John Wiely and sons, Inc, (1995).

10. Savelyev IV "Physics" Mir Publishers, Moscow, first edition, (1980).

11. Holman JP "Thermodynamics" Copyright by Mc Grow-Hill. Inc, (1980).

12. Present RD, "Kinetic Theory of gases" Mc Grow-Hill Book Company, New York, (1938).

13. Jeans JH, "The Dynamical Theory of Gases" Dover Publications, Inc, New York, (1954).

14. R. Ghazy, N. Hendawy, S. Said, H. Nafie, F. El- Mekawey, Accepted Egyptian Journal of Physics (2007).

15. R.C.West, M.G.Astle (Eds), "CRC Handbook of Chemistry and Physics" F-58, E-2, E-357 (1979).

16. F.A. Schwartz, J.E. Prow, Journal of Chem. and Phys. 19, 640,(1951). 